\title{
UNILATERAL LOCALISED GIGANTISM OF THE EXTREMITIES WITH LIPOMATOSIS, ARTHROPATHY AND PSORIASIS
}

\author{
D. M. McCarthy, C. A. Dorr and C. E. Mackintosh, London, England \\ From the Departments of Medicine and Radiology, the Roval Free Hospital, London
}

The association of solitary or multiple lipomata with a variety of radiological abnormalities in bone is recognised by radiologists (Golding 1960, Caffey 1967). However, a review of the literature reveals a heterogenous group of conditions few of which are accompanied by well documented case reports, and the nature of the association remains

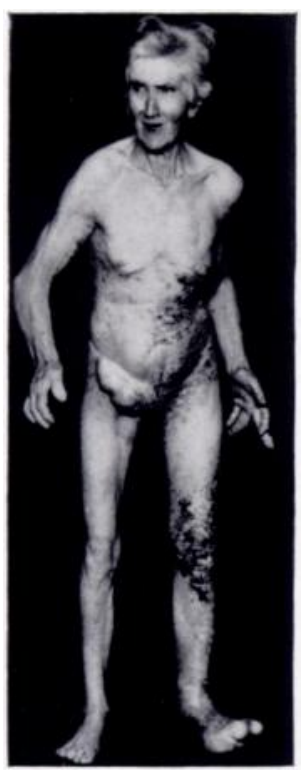

FiG. 1

Theppatient : skin lesions and deformity of the extremities on the left side with large inguinal hernia on the right. unclear. In cases of familial multiple lipomatosis Krabbe and Bartels (1944) and Shanks, Paranchych and Tuba (1957) found no association with specific bone abnormalities. Bick (1936), reviewing 162 cases of lipomata of the extremities, 12 per cent of which were multiple, and White and Hanna (1962), reviewing a further fifty-one cases, did not find any associated changes in bone. Simple subcutaneous lipomata therefore do not appear to evoke changes in bone. Parosteal lipomata causing marked changes in the underlying bone are recorded (Bick 1936) and probably odd cases, described in the past as " malignant lipoma of the extremities" (Weber 1947), were of similar etiology. Intra-osseous medullary lipomata with bone deformity such as Ewing's case, quoted by Bick, are very rare.

This paper describes a specific progressive condition in which lipomatosis was associated with widespread changes in bones and joints together with localised gigantism. The first two cases adequately described were those of Oosthuizen and Barnetson (1947). A third, more complicated case was described by Fainsinger and Harris (1950). Two cases of a similar nature were referred to by Weber (1947) but not described in detail. This appears to be the sixth reported case of the condition and the first in which there has been an association with a psoriaform dermopathy affecting largely the same area of the body. Features of the condition have been summarised by Golding (1960), who entitled it " macrodystrophia lipomatosa." The condition bears a superficial resemblance to congenital hemihypertrophy, though, unlike the latter, it is localised to the extremities. It is unilateral, present from birth, slowly progressive, painless and compatible with a normal life expectancy, though amputation of the gigantic parts for functional and cosmetic reasons has been undertaken in the cases previously described.

Other rare conditions in which bone, joint and skin lesions are associated have been reviewed by Weber (1949) and Scott (1965) but appear unrelated to the condition that we now describe.

\section{CASE REPORT}

A seventy-four-year-old woman was admitted with bronchopneumonia. It was noticed that she had gigantism and deformity of the left hand and foot and a psoriaform rash covering mainly the left half of the body but excluding the head. Her appearance is shown in Figure 1. The deformity in the extremities involved principally the entire left foot and the digits of the left hand, though there was some enlargement of the right fourth toe also. She stated that the abnormalities of the hand and foot had been present from birth and had slowly progressed 
over the years. The skin changes had developed only in recent years and were indistinguishable from psoriasis, apart from the relative sparing of the right side of the body. For over twenty years she had noticed stiffness, immobility and deformity of the small joints of the left hand and foot, later spreading to involve the left wrist and ankle and accompanied in time by fixation of these joints. Photographs of the feet and hands are shown in Figures 2 and 3.

Radiographs of the limbs showed widespread abnormalities, including enlargement of bones, erosions, exostoses, joint destruction and irregular periosteal reaction, the latter affecting

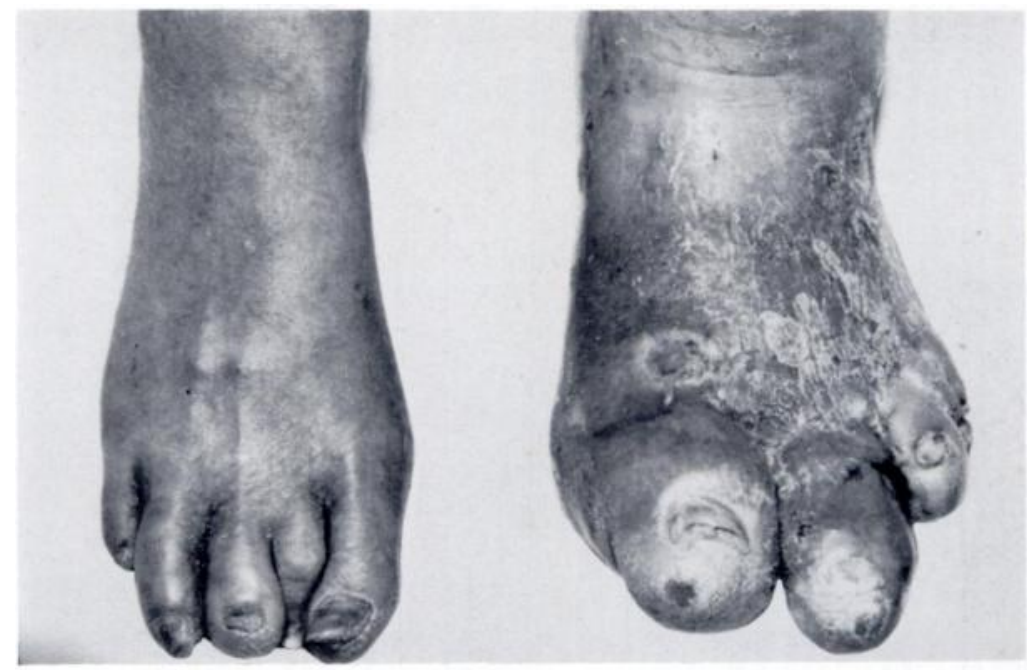

FIG. 2

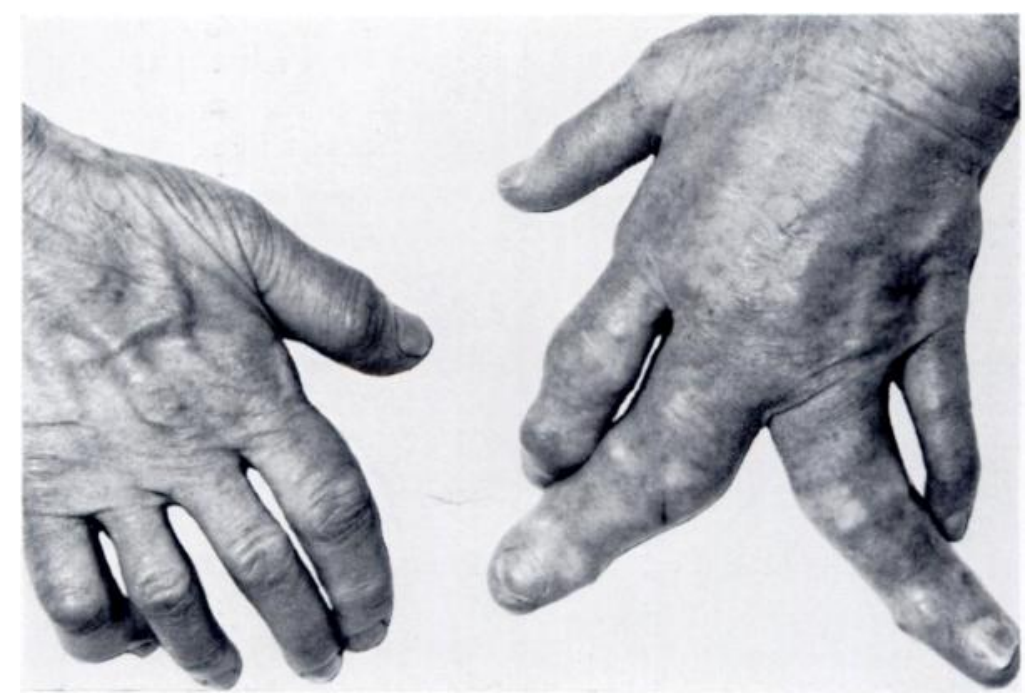

Fig. 3

Figure 2-Photograph of both feet. Note the gigantism and psoriatic change on the left foot. Figure 3-The hands. Note the periarticular lipomata on the digits.

particularly the lower end of the tibia (Fig. 4). The most striking changes were in the left foot (Figs. 2 and 5) with prominent calcaneal spurs and deformity of the ankle (Fig. 6). Characteristic dense bands of trabecular bone were seen running transversely, fusing the head of the second metatarsal with the bases of the proximal phalanges of the first and third toes. Most of the joints of the tarsus and foot were ankylosed, with spindle-shaped deformity of many of the distal joints. The medulla had also been invaded by trabecular bone, and the 
bones of the tarsus, while structurally least affected, showed increased radiolucency. In the left hand (Figs. 3 and 7) the changes were similar but here the striking abnormality was the tremendous increase in the size of the phalanges of the third and fourth digits. Asymmetrical destruction of the distal interphalangeal joints, bilaterally, was also noted and raised the possibility of superimposed psoriatic arthropathy.

In the subcutaneous tissues multiple small lipomata were visible and palpable. averaging about 6 millimetres in diameter. These were most marked in the left hand and in some regions were related to underlying exostoses or erosions. This combination is highly suggestive of macrodystrophia lipomatosa. A moderate kyphosis was present but no other skeletal abnormality. The patient's intelligence appeared to be subnormal, but she was of a cheery disposition and was totally unconcerned with her deformity. Examination of the nervous system, skin, nails, hair, teeth and eyes revealed no other clinical or radiological abnormality: there was a large indirect inguinal hernia in the right groin. Detailed chromosomal studies

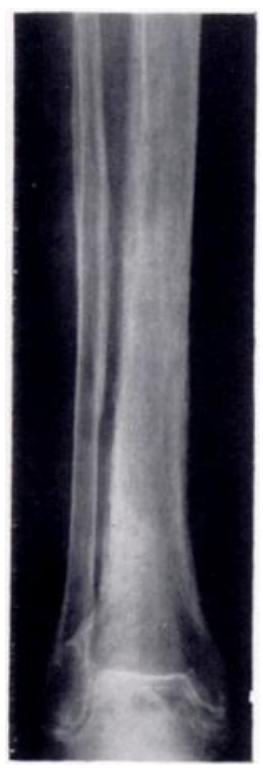

Fig. 4

Radiograph of the left tibia and fibula. could not be performed. Superficial examination of skin-crease and dermal-ridge patterns revealed no evidence of mosaicism, but the skin was stretched and shiny at many points and not easily studied.

A psoriaform rash of considerable severity covered the left side of the body including the trunk. There was marked plaque formation in all areas but particularly on the extensor surfaces of the limbs (Fig. 8). Cutaneous lesions of a similar character, but of lesser severity and extent, were noted on the right arm and on the right side of the trunk. The histology of one of these lesions is shown in Figure 9. Laboratory investigations were otherwise unremarkable.

Among the patient's siblings one twin had been still-born but no abnormalities had been noted in the other. She had married twice, conceived six times, and among her offspring two of unknown sex had been still-born. Of these one was reputed to have been grossly deformed. One girl had died at seven from an obscure wasting disease, and a second boy had died at nineteen in a mental hospital where he had been admitted in childhood suffering from mental deficiency and epilepsy. Two children are alive and normal. The patient is alive and well.

\section{DISCUSSION}

Localised gigantism associated with macrodystrophia lipomatosa must be distinguished from that occurring in other conditions. The superficial resemblance is with congenital hemihypertrophy, but while a review of the literature (Ringrose, Jabbour and Keele 1965: Panday, Kelkar, Parulekar and Sen 1966) reveals the occurrence of a number of associated abnormalities in this condition, progressive arthropathy is not a feature. Furthermore, hemihypertrophy also involves the head and trunk, while macrodystrophia involves only the extremities. The other congenital condition which may be strikingly similar is Von Recklinghausen's multiple neurofibromatosis. The occurrence of multiple subcutaneous nodules, bony abnormalities and local gigantism in both conditions may cause confusion, but the extensive ankylosis of distal joints in macrodystrophia and the presence of "café-au-lait " spots or epithelial fibromata in neurofibromatosis help to differentiate the conditions clinically. Radiologically, bone changes in neurofibromatosis (Hunt and Pugh 1961, Edeiken and Hodes 1967) have a characteristically " wavy outline " and are often related to the course of an affected nerve. Local gigantism has also been described in Ollier's disease (Chigirinskii 1957) but the distribution of the dyschondroplasia and endochondromata usually ensure rapid identification of the cause. In congenital macrodactyly, a condition probably related to syndactyly and polydactyly (Johnston and Davis 1953), digital enlargement occurs, but is not associated with lipomata, arthropathy, 
deformity or radiological abnormalities of the kind seen here. Congenital arteriovenous fistulae (Horton 1932) or haemangiomata (Caffey 1967) may lead to local gigantism of an extremity but the limb, apart from the vascular abnormality and the increased size, is structurally normal. In these conditions an elevated temperature, the presence of bruits or

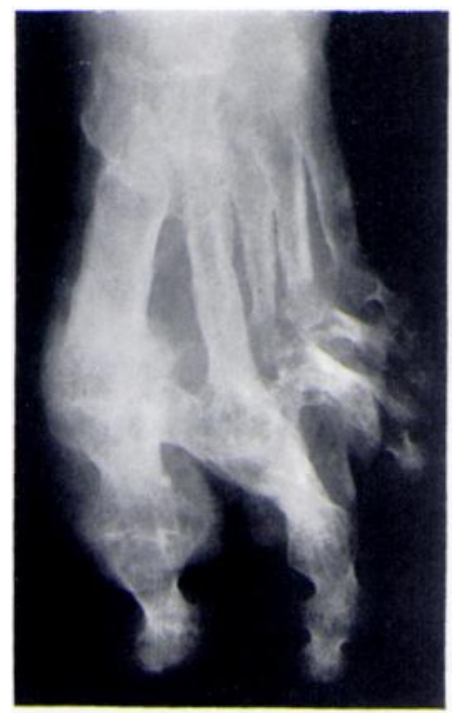

FIG. 5

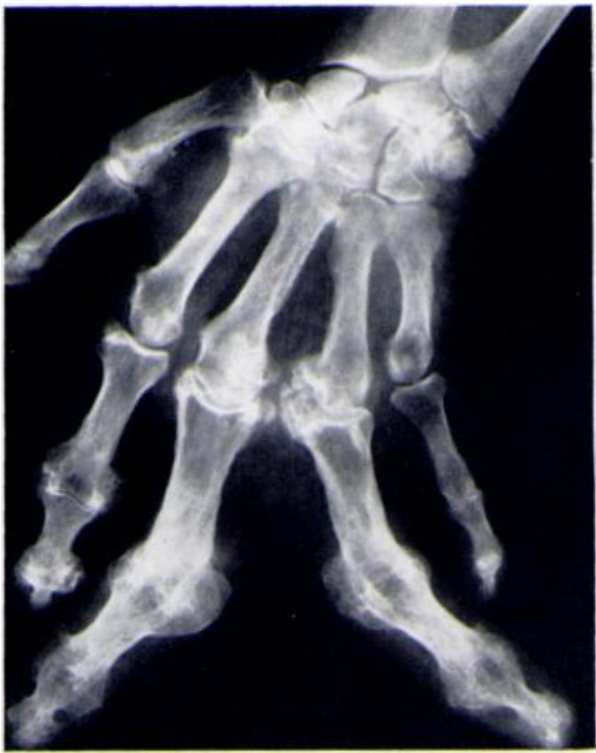

FIG. 7

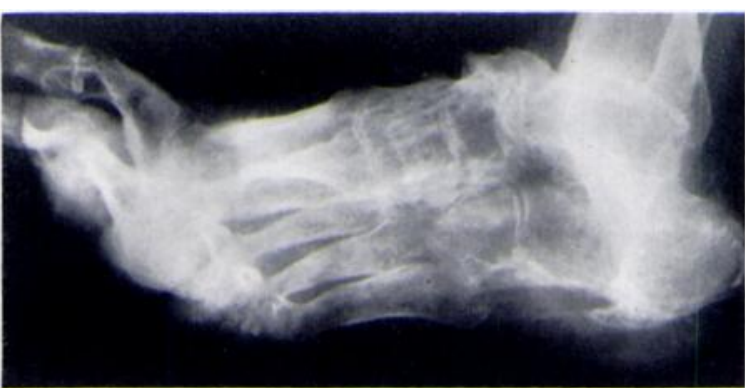

Fig. 6
FICis. 5 AND 6

Figure 5 Radiograph of the left foot. Figure 6 Lateral radiograph of the left foot.

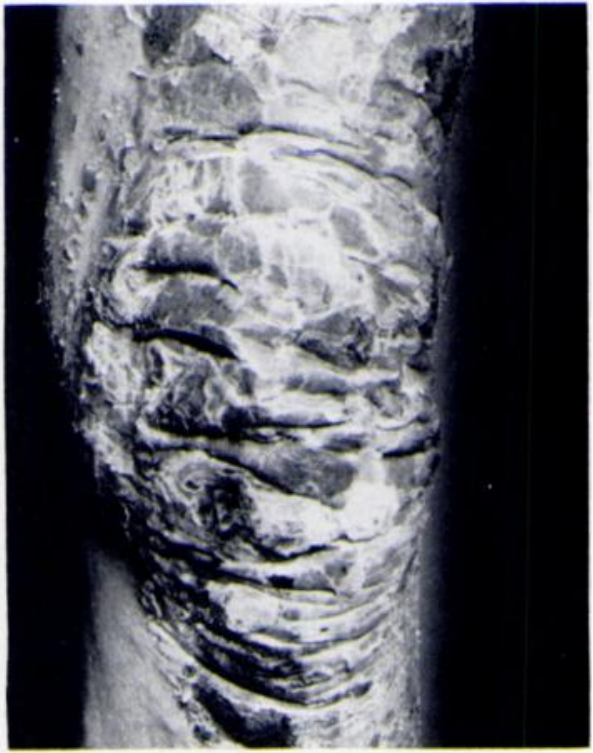

Fig. 8

Figure 7 Radiograph of the left hand. Figure 8 Skin changes overlying the left knee.

of superficial venous dilation may give a clue to the diagnosis of the underlying vascular abnormality.

Hypertrophy of the extremities seen in melorrheostosis is always accompanied by severe pain, which is often the presenting feature of the disease (Mercer and Duthie 1964, Caffey 1967). Radiologically the disease gives rise to the characteristic appearance of " candle grease bones," in which areas of sclerosis alternate with areas of mature and immature bone. Here the joints are arthritic but not ankylosed or spindled, and the growing ends of the long bones are mostly

VOL. 51 B, NO, 2, MAY 1969) 


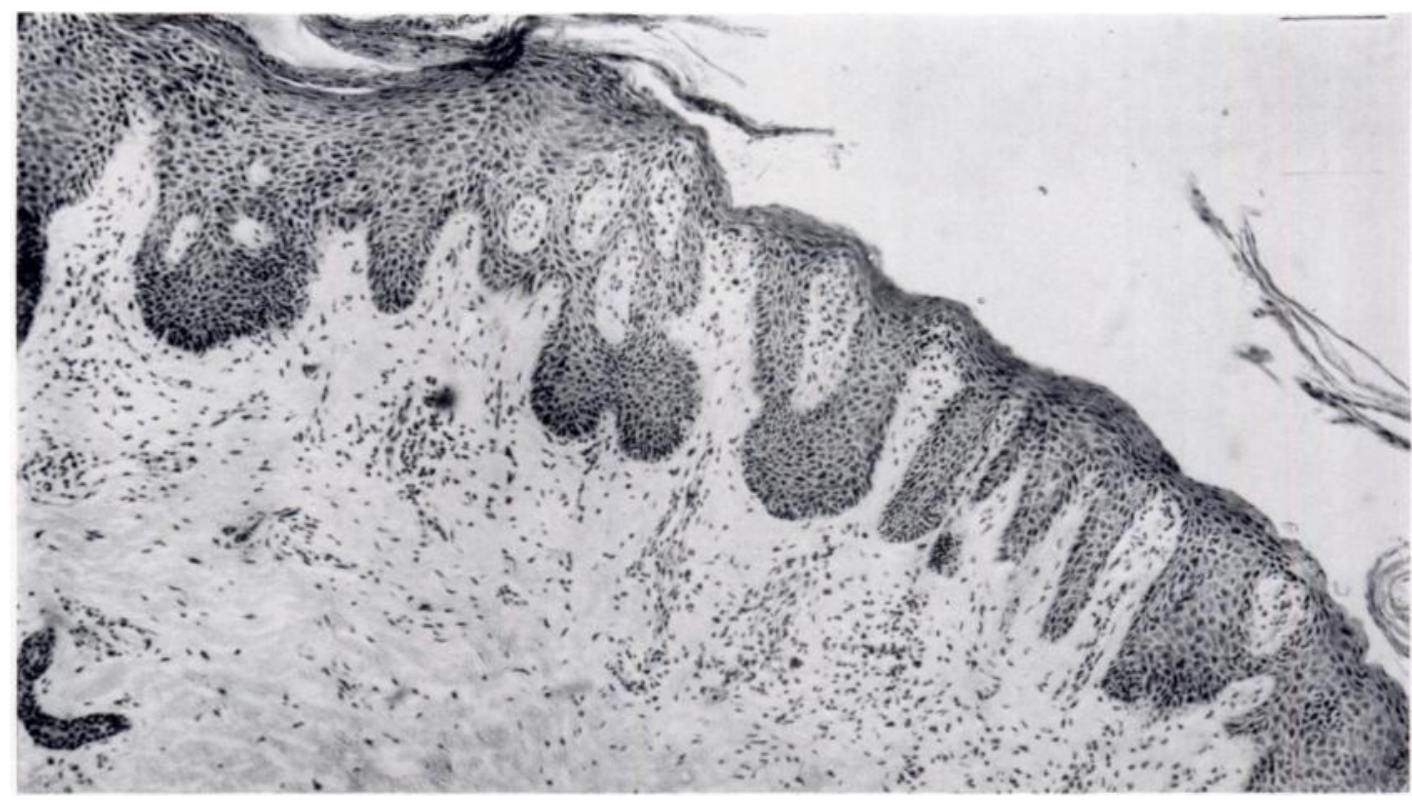

FIG. 9

Histological appearance of biopsy from the skin lesion on the trunk. (Haematoxylin and eosin, $\times 80$.)

affected. In congenital lymphoedema, presenting with local gigantism, the radiographic appearance of the bones is normal. Other interesting aspects of lateral asymmetry are discussed by Halperin (1931) and Ringrose et al. (1965), but are not significant in the present discussion.

The etiology, pathogenesis and genetic background of macrodystrophia lipomatosa are unknown. Oosthuizen and Barnetson, who performed detailed histological studies of the amputated extremities, wrote: "we have faute-de-mieux used the term "lipomatosis" throughout to describe the fatty abnormality present, though we are uncertain of the essential nature of the pathological process," and our use of the term is similarly qualified. None of the described cases has been absolutely identical with the others, but allowing for minor variations they appear to form a distinct group.

The lesions in the foot in our case, involving particularly the calcaneus and metatarsal bones, but sparing those of the tarsus, are strikingly similar to those reported in the two cases of Barnetson, though in those cases the hands were normal. The hand lesions which we have described closely resemble those described in the case of Fainsinger and Harris, though their patient also had multiple vascular anomalies of the skin not present in ours. In macrodystrophia lipomatosa, lesser lesions may also be found in the bones of the opposite side (Golding 1960), and in the case of Fainsinger and Harris the opposite foot was also involved. Lesser dystrophic abnormalities were noted in the radiographs of the right hand and foot of our patient and, although some changes may be due to the development of complicating psoriatic arthropathy, the presence of the trabecular bands, joint spindling and early ankylosis of the metatarsophalangeal joints suggest involvement of the right side by the same generalised process.

The association of the disease with the severe psoriaform rash occurring mainly, though not entirely, on the same side of the body, is not previously recorded and is of uncertain significance. It is nevertheless interesting to note that the distribution of the skin lesions follows that of the underlying lipomatous dysplasia. The skin lesions were refractory to a variety of forms of therapy normally helpful in psoriasis, but otherwise were typical. A number of metabolic disorders have been described in psoriasis, including abnormalities of lipid metabolism (Ormsby and Montgomery 1954), but lipomatosis of the type seen here has not been associated with skin lesions in the previously described cases. 


\section{SUMMARY}

1. A woman of seventy-four presenting with gigantism of the left hand and foot, lipomatosis, progressive arthropathy and psoriasis is described.

2. The associations of the various conditions are examined in the light of the previously reported cases and the differential diagnosis of this condition (macrodystrophia lipomatosa) from other causes of localised gigantism is discussed.

Our thanks are due to Dr Ian A. D. Bouchier for permission to study the case, to Dr W. B. Young of the Radiological Department, Dr P. Scheuer of the Department of Pathology, and Dr I. Sarkany, dermatologist, for helpful discussions, and to the Photographic Department of the hospital for valuable assistance.

\section{REFERENCES}

Bick, E. M. (1936): Lipoma of the Extremities. Annals of Surgery, 104, 139.

Caffey, J. (1967): Pediatric X-ray Diagnosis. .Fifth edition, pp. 802, 857, 1020. Chicago: Year Book Medical Publishers Inc.

ChigirinsKII, L. M. (1957): Sochetanie bolezni Ol'e s chastichnym gigantizmom. Ortopediia, travmatologiia, i protezirovanie, 18, (1) 67.

Edeiken, J., and Hodes, P. J. (1967): Roentgen Diagnosis of Diseases of Bone, pp. 6-126. Baltimore: Williams Wilkins Co.

FAINSINGER, M. H., and HARRIS, L. C. (1950): Generalised Lipomatosis Involving Bone. British Journal of Radiology, 23, 274.

Golding, F. C. (1960): Rare Diseases of Bone. In Modern Trends in Diagnostic Radiology (Third Series), p. 147. Edited by J. W. McLaren. London: Butterworth \& Co. (Publishers) Ltd.

HalPerin, G. (1931): Normal Asymmetry and Unilateral Hypertrophy. Archives of Internal Medicine, 48, 676.

Horton, B. T. (1932): Hemihypertrophy of Extremities Associated with Congenital Arteriovenous Fistula. Journal of the American Medical Association, 98, 373.

Hunt, J. C., and Pugh, D. G. (1961): Skeletal Lesions in Neurofibromatosis. Radiology, 76, 1.

Johnston, O., and Davis, R. W. (1953): On the Inheritance of Hand and Foot Anomalies in Six Families. American Journal of Human Genetics, 5, 356.

Krabbe, K. H., and Bartels, E. D. (1944): La Lipomatose Circonscrite Multiple. Copenhagen: Einar Munksgaard.

Mercer, Sir W., and Duthie, R. B. (1964): Orthopaedic Surgery. Sixth edition, pp. 155-156. London: Edward Arnold (Publishers) Ltd.

Oosthuizen, S. F., and Barnetson, J. (1947): Two Cases of Lipomatosis Involving Bone. British Journal of Radiology, 20, 426.

Ormsby, O. S., and Montgomery, H. (1954): Diseases of the Skin. Eighth edition, pp. 316-317. London: Henry Kimpton.

Panday, S. R., Kelkar, M. D., Parulekar, G. B., and Sen, P. K. (1966): Congenital Hemihypertrophy: Report of two cases and review of the literature. Journal of Postgraduate Medicine, 12, 79.

Ringrose, R. E., Jabbour, J. T., and Keele, D. K. (1965): Hemihypertrophy. Pediatrics, 36, 434.

Scotr, J. T. (1965): Joint Involvement in Bone Diseases. In Progress in Clinical Rheumatology, p. 304. Edited by A. St J. Dixon. London: J. \& A. Churchill Ltd.

Shanks, J. A., Paranchych, W., and Tuba, J. (1957): Familial Multiple Lipomatosis. Canadian Medical Association Journal, 77, 881.

Weber, F. P. (1947): Rare Diseases and Some Debatable Subjects. Second edition, p. 28. London: Staples Press.

Weber, F. P. (1949): Further Rare Diseases. (Combined osseous and dermal dysplasias), p. 127. London: Staples Press.

White, W. L., and Hanna, D. C. (1962): Troublesome Lipomata of the Upper Extremity. Journal of Bone and Joint Surgery, 44-A, 1353. 